\title{
Malignant Ossifying Fibromyxoid Tumor
}

National Cancer Institute

\section{Source}

National Cancer Institute. Malignant Ossifying Fibromyxoid Tumor. NCI Thesaurus. Code C121774.

An ossifying fibromyxoid tumor characterized by the presence of high grade nuclear features or increased cellularity and more than two mitotic figures per 50 HPFs. 